\title{
Association of Kidney Disease Quality of Life (KDQOL-36) with mortality and hospitalization in older adults receiving hemodialysis
}

Rasheeda K. Hall ${ }^{1,2^{*}}$ (D) Alison Luciano ${ }^{4}$, Carl Pieper ${ }^{3}$ and Cathleen S. Colón-Emeric ${ }^{1,4}$

\begin{abstract}
Background: For older adults receiving dialysis, health-related quality of life is not often considered in prognostication of death or future hospitalizations. To determine if routine health-related quality of life measures may be useful for prognostication, the objective of this study is to determine the extent of association of Kidney Disease Quality of Life (KDQOL-36) subscales with adverse outcomes in older adults receiving dialysis.

Methods: This is a longitudinal study of 3500 adults aged $\geq 75$ years receiving dialysis in the United States in 2012 and 2013. We used Cox and Fine and Gray models to evaluate the association of KDQOL-36 subscales with risk of death and hospitalization. We adjusted for sociodemographic variables, hemodialysis access type, laboratory values, and Charlson index.

Results: Three thousand one hundred thirty-two hemodialysis patients completed the KDQOL-36. From KDQOL-36 completion date in 2012, 880 (28.1\%) died and 2023 (64.6\%) had at least one hospitalization over a median follow-up of 512 and 203 days, respectively. Cohort members with a SF-12 physical component summary (PCS) in the lowest quintile had an increased adjusted risk of death [hazard ratio (HR), 1.55, 95\% confidence interval (Cl) 1.19-2.03] and hospitalization (HR, 1.29,95\% Cl 1.09-1.54) compared with those with scores in the highest quintile. Cohort members with a SF-12 mental component summary in the lowest quintile had an increased risk of hospitalization (HR, 1.39, 95\% Cl 1.17-1.65) compared with those in the highest quintile. In adjusted analyses, there was no association between the symptoms of kidney disease, effects of kidney disease, and burden of kidney disease subscales with time to death or first hospitalization. Competing risk models showed similar HRs.
\end{abstract}

Conclusions: Among the KDQOL-36 subscales, the SF-12 PCS demonstrates the strongest association with both death and future hospitalizations in older adults receiving hemodialysis Further research is needed to assess the value this subscale may add to prognostication.

Keywords: Geriatric nephrology, Health-related quality of life, Competing risks, SF-12, Prognostication

\footnotetext{
* Correspondence: rasheeda.stephens@dm.duke.edu

'Durham VA Geriatric Research, Education and Clinical Center, 508 Fulton Street, Durham, NC 27705, USA

2Duke University Medical Center, Division of Nephrology, Department of Medicine, Box DUMC 2747, 2424 Erwin Road Suite 605, Durham, NC 27710, USA

Full list of author information is available at the end of the article
} 


\section{Background}

Health-related quality of life is increasingly recognized as an important patient-centered outcome for older adults with kidney disease, many of whom have limited lifeexpectancy and a significant symptom burden [1]. Because health-related quality of life instruments assess self-rated health through items related to physical health, mental health, symptoms and limitations, another potential use for health-related quality of life assessment may be prognostication of adverse outcomes in these patients. Such prognostic information would help clinicians identify a subset of patients at increased risk for death and hospitalization who may benefit from interventions both to reduce the risk of these outcomes and to prepare for treatment decisions that may lie ahead [2, 3]. Several studies in general population cohorts of older adults, older adults with specific chronic conditions, and cohorts of kidney disease in adults of all ages demonstrate the relationship between health-related quality of life and survival [4-18]. To our knowledge, prior studies have not examined the association of health-related quality of life with mortality or hospitalizations in cohorts limited to prevalent older adults receiving maintenance dialysis. While many of the available prognostic tools in older adults with kidney disease include markers suggestive of functional disability (e.g., mobility disability, long-term care, assistance with activities of daily living), none, to our knowledge, have incorporated health-related quality of life [19-23]. Because functional status often determines health-related quality of life and is a stronger predictor of adverse outcomes than disease-specific measures in older adults in the general population [24], we hypothesized that health-related quality of life from the commonly administered Kidney Disease Quality of Life-36 instrument (KDQOL-36) may be useful for prognostication. Towards testing this hypothesis, we first need to determine the extent of association of KDQOL-36 subscale scores with adverse outcomes in older adults. Thus, we conducted a cohort study to determine the strength of the association between subscales on the KDQOL-36 and mortality and hospitalization in a cohort of older adults receiving maintenance dialysis.

\section{Methods}

\section{Study design and data source}

We performed a cohort study using data assembled from a large dialysis organization's (LDO) clinical records during 2012 and 2013. Derived from the LDO's census of patients within the United States, this cohort included a nationally representative random sample of 3500 dialysis patients age 75 years and older as of January 1, 2012 who had KDQOL-36 responses in 2012 and were followed until clinical event (death or first hospitalization), or end of the study period, December 31, 2013. For each cohort member, we received non-identifiable patient-level clinical data including dates of clinical events, comorbidities, and laboratory data from January 1, 2012 to December 31, 2013. We selected the cohort size and follow-up period to accommodate financial resource constraints. This study was approved by the Duke University Institutional Review Board.

\section{Study population}

As part of routine clinical care endorsed by the United States' Centers for Medicare and Medicaid Services (CMS), dialysis staff administered the KDQOL-36 to patients in this cohort at least once a year. Dialysis unit social workers either supplied a paper copy of the KDQOL-36 for self-administration or they helped patients complete it during dialysis if they were unable to self-administer. Of the 3500 patients included in this cohort, we excluded one patient from analyses because multiple KDQOL-36 assessments with inconsistent responses were documented in a single day. An additional 232 (6.6\%) patients were excluded because they were missing information necessary for calculation of KDQOL-36 subscale scores (e.g., at least one of the SF-12 items or all items within an individual kidney disease-specific subscale on the KDQOL-36). Because patients receiving peritoneal dialysis (PD) often differ from hemodialysis patients, we excluded an additional 135 cohort members who were receiving PD, resulting in final analytic sample size of 3132 . We show characteristics of patients who were included and excluded from analyses in Additional file 1: Table S1.

\section{Exposure variables}

The KDQOL-36 is a 36-item health-related quality of life instrument adapted from the original 134-item KDQOL, an instrument principally developed to measure quality of life of dialysis patients [25]. Because there is no currently accepted overall KDQOL-36 score that incorporates all of its subscales [26], and to be consistent with prior studies [6], we calculated scores for the following five subscales of the KDQOL-36 separately: 1) SF-12 physical component summary (PCS), 2) SF-12 mental component summary (MCS), 3) Burden of kidney disease, 4) Symptoms of kidney disease and 5) and Effects of kidney disease. KDQOL-36 subscale scores ranged from 0 to 100 , and lower scores indicated worse self-reported quality of life. These subscale scores were categorized into quintiles (first quintile = lowest scores, fifth quintile $=$ highest scores).

\section{Covariates}

We identified the following baseline characteristics present on the date of KDQOL-36 administration in 2012: age, gender, race (e.g., Caucasian, African-American, Hispanic, or 
other), whether patients were Medicaid eligible (a proxy for socioeconomic status), Charlson comorbidity index [27], hemodialysis access type (e.g., arteriovenous fistula, arteriovenous graft, or central venous catheter), and length of time on dialysis (defined as time between each patient's first dialysis treatment and the date of KDQOL-36 administration during the study period). We also obtained relevant laboratory measures [albumin, hemoglobin, dialysis adequacy $(\mathrm{Kt} / \mathrm{V})$ ] typically collected less than 1 month from the date of KDQOL-36 administration. For example, mean time between serum albumin levels and KDQOL-36 administration was $13.5(\mathrm{SD}=10.3)$ days.

\section{Outcomes}

Outcomes of interest were time to death and time to first hospitalization and were measured from date of KDQOL-36 administration through event date. We defined first hospitalization as the date of a hospitalization occurring in 2012. Among 3132 with complete KDQOL36 data, five deaths and 37 hospitalizations occurred before the documented date of KDQOL-36 administration, so cohort members with these events were not included in survival analyses.

\section{Statistical analysis}

To determine the extent to which KDQOL-36 subscale scores are associated with death and/or hospitalizations in older adults receiving dialysis, we conducted the following three analyses: 1) a Cox proportional hazards regression model to measure the association of all KDQOL-36 subscales with time to death, 2) a Cox proportional hazards regression model to measure the association of all KDQOL-36 subscales with time to first hospitalization, and 3) a competing risk analysis to measure the association between KDQOL-36 subscales and time to first hospitalization after KDQOL-36 administration, with death as the competing event. In these analyses, baseline socio-demographic (age, sex, race/ethnicity, presence of Medicaid insurance - as a proxy for low socioeconomic status) and clinical (albumin, hemoglobin, Kt/V, Charlson comorbidity index, access type, and time since dialysis initiation) variables were identified a priori as covariates based on previous research [28-31]. Cox analyses were repeated, modeling individual subscales in isolation. We used Lowess curve deviation for horizontal of Martingale residuals to assess linearity of continuous covariates. We assessed categorical covariates for violation of the proportional hazards assumptions (i.e., non-random pattern of Schoenfeld residuals plot versus log time). Because serum albumin did not meet the proportional hazards assumption, we performed stratified Cox models to allow the form of the underlying hazard function to vary across levels of albumin.
For the Cox regression models, subjects were censored at the date of the event (death or first hospitalization after KDQOL-36 administration) or at the end of the study period, December 31, 2013. We evaluated goodness of fit using Schoenfeld residuals, Cox-Snell residuals, and differences in fit due to observation deletion. We assessed the joint relevance of including the KDQOL-36 subscales in models for death and hospitalization by comparing fit between models with and without the subscales to obtain a global likelihood ratio (LR) statistic [32]. We estimated concordance (Cstatistic) via Harrell's $C$ for Cox regression models [33]. For the competing risk analysis, KDQOL-36 assessment was treated as study start date, first hospitalization post assessment as event of interest, and death as competing event. We used the Fine and Gray method to estimate unadjusted and multi-adjusted sub-distribution relative hazards of hospitalization [34, 35]. Surviving participants with no hospitalizations during the study period were right censored. All analyses were performed using Stata version SE 15.

\section{Results \\ Cohort characteristics}

Of the 3132 patients in the analytic cohort, at baseline, the average age was $80.5(4.4)$ years, $50.1 \%(n=1570)$ were male, $22.9 \%(n=675)$ received Medicare and Medicaid insurance (dual eligible), time since dialysis initiation was 5.9 (2.9) years, average Charlson index was 7.4 (1.3), and the majority of these $(64.5 \%, n=2018)$ had an arteriovenous fistula (Table 1). Table 2 shows the distribution of KDQOL-36 subscale scores. No cohort members achieved the maximum score for SF-12 PCS or MCS.

\section{Association between KDQOL-36 subscales and mortality}

Over the study period, $28.1 \%(n=880)$ of the cohort members died after date of completion of the KDQOL36 (median follow-up of 512, range, 1-730) days. In unadjusted analyses, cohort members in the first quintile (relative to the fifth quintile) for all five KDQOL-36 subscales had a higher hazard of death (Additional file 1: Table S2). After adjustment for sociodemographic characteristics, time since dialysis initiation, Charlson index, access type, and laboratory values, these associations were attenuated (Additional file 1: Table S3). With all five KDQOL-36 subscales combined in a model with covariates, only cohort members in the first quintile for the SF-12 PCS maintained a significantly higher hazard of death [hazard ratio (HR), 1.55, 95\% confidence interval (CI) 1.19-2.03] when compared with patients in the fifth quintile (Fig. 1). In this model, race, gender, time since dialysis initiation, hemoglobin, and Charlson index also maintained significant associations with time to 
Table 1 Baseline Cohort Characteristics

\begin{tabular}{|c|c|}
\hline Variable & $\begin{array}{l}\text { Total Sample } \\
(n=3132)^{\mathrm{a}}\end{array}$ \\
\hline Age, year & $80.5(4.4)$ \\
\hline \multicolumn{2}{|l|}{ Race, $(n=3131)$} \\
\hline Caucasian & $1590(50.8 \%)$ \\
\hline African-American & $893(28.5 \%)$ \\
\hline Hispanic & $420(13.4 \%)$ \\
\hline Other & $228(7.3 \%)$ \\
\hline \multicolumn{2}{|l|}{ Sex } \\
\hline Women & $1562(49.9 \%)$ \\
\hline Men & $1570(50.1 \%)$ \\
\hline \multicolumn{2}{|l|}{ Insurance Status, $(n=2945)$} \\
\hline Enrolled in Medicaid & $675(22.9 \%)$ \\
\hline Not Enrolled in Medicaid & $2270(77.1 \%)$ \\
\hline \multicolumn{2}{|l|}{ Medical History } \\
\hline Time on Dialysis (years) & $5.9(2.9)$ \\
\hline $\mathrm{Kt} / \mathrm{N}^{\mathrm{b}},(n=3116)$ & $1.7(0.3)$ \\
\hline Hemoglobin $(\mathrm{g} / \mathrm{dL})^{\mathrm{b}},(n=3131)$ & $10.8(1.0)$ \\
\hline Albumin $(\mathrm{gm} / \mathrm{dL})^{\mathrm{b}},(n=3131)$ & $3.9(0.3)$ \\
\hline Charlson comorbidity index & $7.4(1.3)$ \\
\hline \multicolumn{2}{|l|}{ Access Type, $(n=3131)$} \\
\hline Catheter & $294(9.4 \%)$ \\
\hline Arteriovenous fistula & $2018(64.5 \%)$ \\
\hline Arteriovenous graft & $819(26.2 \%)$ \\
\hline
\end{tabular}

Data expressed as $\mathrm{n}(\%)$ or mean $\pm \mathrm{SD}$

aalues based on total of 3132 patients who completed all KDQOL-36 items in 2012, unless otherwise specified

${ }^{b}$ Laboratory values documented closest to the date of the first KDQOL-36 administration in 2012

death (Additional file 1: Table S4). Compared to a regression model that included sociodemographic characteristics, time since dialysis initiation, Charlson index, access type, and laboratory values, overall model fit improved with block addition of the five KDQOL-36 subscales $\left(\operatorname{LR~} X^{2}(d f=20)\right)=42.64 ; p$-value $\left.=0.002\right)$. The
C-statistic $\mathrm{w} /$ bootstrapping for this model with all five KDQOL-36 subscales was 0.63 (95\% CI 0.61-0.65).

\section{Associations of KDQOL-36 subscales with first hospitalization} Over the study period, $64.6 \%(n=2023)$ of the cohort members were hospitalized at least once after date of completion of the KDQOL-36 (median follow-up of 203 (range, 1-730) days. Among those who were hospitalized, $730(36.1 \%)$ later died during the observation period. However, 92.2\% $(n=673)$ died at least 7 days after the hospitalization. The average length of stay was 5.6 (7.6) days. Although nearly $50 \%$ of hospitalization diagnoses were unavailable, the most common causes of hospitalization that were documented were shortness of breath $(n=154,7.6 \%)$, pneumonia $(n=105,5.2 \%)$, and chest pain $(n=94,4.6 \%)$. In unadjusted analyses, cohort members in the first quintile (relative to the fifth quintile) for all five KDQOL-36 subscales had a higher hazard of hospitalization (Additional file 1: Table S2). After adjustment for sociodemographic characteristics, time since dialysis initiation, Charlson index, access type, and laboratory values, these associations were attenuated (Additional file 1: Table S5). With all five KDQOL-36 subscales combined in a model with covariates, cohort members in the first quintile (relative to the fifth quintile) for the SF-12 MCS (HR, 1.39, 95\% CI 1.17-1.65) and SF-12 PCS (HR, 1.29, 95\% CI 1.09-1.54) maintained a higher hazard of hospitalization (Table 3). Compared to a regression model that included sociodemographic characteristics, time since dialysis initiation, Charlson index, access type, and laboratory values, overall model fit improved with block addition of the five KDQOL-36 subscales $\left(\mathrm{LR} \mathrm{X}^{2}(\mathrm{df}=20)\right)=62.33$; $p$-value $<0.001)$. The $\mathrm{C}$-statistic $\mathrm{w} /$ bootstrapping for this model with all five KDQOL-36 subscales was 0.58 (95\% CI, 0.56-0.59). In the competing risk model, these associations were similar [SF-12 MCS, subdistribution hazard ratio (sdHR), 1.38, 95\% CI 1.16-1.64; SF-12 PCS, sdHR, $1.31,95 \%$ CI 1.10-1.56] (Table 3).

Table 2 Means and Quintile Ranges for Kidney Disease Quality of Life-36 Subscale Scores ${ }^{a}$

\begin{tabular}{|c|c|c|c|c|c|c|}
\hline & Mean \pm SD & 1st Quintile & 2nd Quintile & 3rd Quintile & 4th Quintile & 5th Quintile \\
\hline SF-12 Physical Component Score & $34.5 \pm 9.9$ & $\begin{array}{l}11.9 \text { to } 25.5 \\
(\mathrm{~N}=627)\end{array}$ & $\begin{array}{l}25.5 \text { to } 30.4 \\
(\mathrm{~N}=626)\end{array}$ & $\begin{array}{l}30.4 \text { to } 36.5 \\
(N=627)\end{array}$ & $\begin{array}{l}36.5 \text { to } 43.8 \\
(N=626)\end{array}$ & $\begin{array}{l}43.8 \text { to } 63.6 \\
(\mathrm{~N}=626)\end{array}$ \\
\hline SF-12 Mental Component Score & $50.9 \pm 10.4$ & $\begin{array}{l}14.6 \text { to } 40.9 \\
(\mathrm{~N}=627)\end{array}$ & $\begin{array}{l}40.9 \text { to } 49.4 \\
(\mathrm{~N}=626)\end{array}$ & $\begin{array}{l}49.4 \text { to } 55.8 \\
(\mathrm{~N}=627)\end{array}$ & $\begin{array}{l}55.8 \text { to } 60.6 \\
(N=626)\end{array}$ & $\begin{array}{l}60.6 \text { to } 72.2 \\
(\mathrm{~N}=626)\end{array}$ \\
\hline Symptoms/Problems & $78.5 \pm 15.6$ & $\begin{array}{l}14.6 \text { to } 65.9 \\
(\mathrm{~N}=627)\end{array}$ & $\begin{array}{l}66.7 \text { to } 77.1 \\
(N=654)\end{array}$ & $\begin{array}{l}77.3 \text { to } 85.4 \\
(N=689)\end{array}$ & $\begin{array}{l}86.4 \text { to } 91.7 \\
(N=598)\end{array}$ & $\begin{array}{l}92.5 \text { to } 100.0 \\
(N=564)\end{array}$ \\
\hline Effects of Kidney Disease & $74.3 \pm 21.3$ & $\begin{array}{l}0.0 \text { to } 56.3 \\
(N=674)\end{array}$ & $\begin{array}{l}57.1 \text { to } 71.9 \\
(N=637)\end{array}$ & $\begin{array}{l}75.0 \text { to } 84.4 \\
(N=649)\end{array}$ & $\begin{array}{l}85.0 \text { to } 93.8 \\
(N=611)\end{array}$ & $\begin{array}{l}95.0 \text { to } 100.0 \\
(N=561)\end{array}$ \\
\hline Burden of Kidney Disease & $52.6 \pm 29.4$ & $\begin{array}{l}0.0 \text { to } 25.0 \\
(N=814)\end{array}$ & $\begin{array}{l}31.3 \text { to } 43.8 \\
(N=587)\end{array}$ & $\begin{array}{l}50.0 \text { to } 62.5 \\
(N=600)\end{array}$ & $\begin{array}{l}66.7 \text { to } 81.3 \\
(N=585)\end{array}$ & $\begin{array}{l}87.5 \text { to } 100.0 \\
(N=546)\end{array}$ \\
\hline
\end{tabular}

${ }^{a}$ Values from minimum to maximum for each quintile are shown. $N=3132$ 


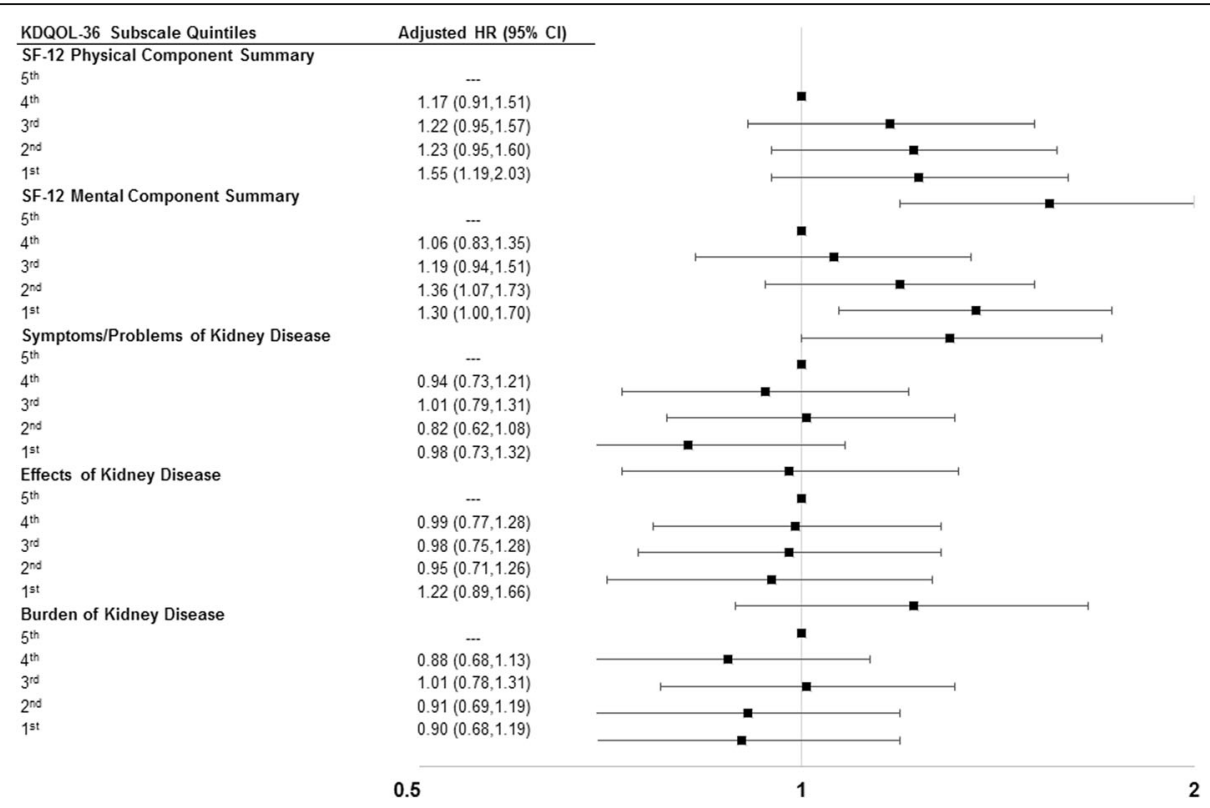

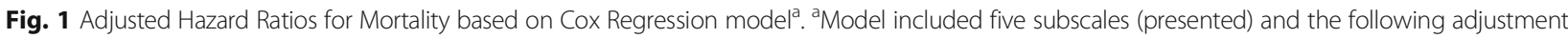
factors as of first KDQOL-36 administration after January 1, 2012: age, race, sex, Medicaid status, time on dialysis (years), Kt $N$, hemoglobin, charlson comorbidity index score, and access type (catheter, arterialvenous fistula, arterialvenous graft). Model results (hazard ratios and 95\% confidence intervals) for covariates presented in Additional file 1: Table S4

\section{Discussion}

A growing number of patients treated with maintenance dialysis are older, frail and have functional impairment $[29,36]$. Among populations of older adults in the general population, the presence of functional impairment is often a more powerful predictor of adverse outcomes than traditional disease-based measures [24]. Better prognostic tools that incorporate information on functional status could be helpful in supporting discussions about prognosis, treatment preferences and goals of care for many of these vulnerable patients. As a first step, the current study estimated the association between a patient-reported outcome measure that is efficiently and reliably collected as part of routine clinical care, the KDQOL-36 subscales, and two important and easily measured endpoints: mortality and hospitalization. Among KDQOL-36 subscales only SF-12 PCS demonstrates significant associations with both mortality and hospitalization risk. If combined with other prognostic tools, this subscale may yield a modest improvement in prediction of remaining lifetime and future hospitalizations in older adults receiving dialysis. Although many older adults receiving maintenance dialysis have limited life expectancy and significant comorbidity burden, as reflected in the generally low health-related quality of life observed in this population, their SF-12 PCS responses were independently associated with mortality. To date, there are no observational studies or clinical practice guidelines to guide how low self-reported physical health (or SF-12 PCS) should impact care for dialysis patients. However, our study demonstrates that this patient-reported information could add a distinct construct to existing prediction tools that rely on clinical gestalt and/or comorbidities, lab values, and crude measures of functional status (e.g., impaired mobility or dependency in activities of daily livings) [3]. Our results in patients aged $\geq 75$ years extends that of other studies demonstrating that the SF-12 PCS (or its larger form, SF-36 PCS) is associated with survival in younger patients receiving dialysis, patients with $\mathrm{CKD}$, community dwelling older adults, and older adults with other chronic conditions $[6-10,13,37]$. Similar to a large Dialysis Outcomes and Practice Patterns Study that evaluated the association of KDQOL-SF (instead of KDQOL-36) subscales with mortality in a younger cohort (mean age, 60.5 \pm 15.2 ) [8], we also identified weaker or non-existent associations of the SF-12 MCS and the kidney disease-specific subscales with mortality, suggesting these subscales, compared to SF-12 PCS, may be less likely to improve efforts to predict the probability of mortality in older adults receiving dialysis [38].

Consistent with prior evidence in a wider age range of the dialysis population [8], our analyses reveal that hospitalizations occur more quickly among cohort members who report low self-rated health on the SF-12 [39]. This association may be explained by frailty as it often contributes to limited physical function, and increases vulnerability to acute stressors that warrant 
Table 3 Adjusted Analyses for Risk of Hospitalization with and without Competing Mortality

\begin{tabular}{|c|c|c|}
\hline Quintile & $\begin{array}{l}\text { Adjusted HR } \\
(95 \% \mathrm{Cl})\end{array}$ & $\begin{array}{l}\text { Adjusted sdHR } \\
(95 \% \mathrm{Cl})\end{array}$ \\
\hline \multicolumn{3}{|l|}{ Physical } \\
\hline $1 s t$ & $1.29(1.09,1.54)$ & $1.31(1.10,1.56)$ \\
\hline 2nd & $1.13(0.96,1.33)$ & $1.14(0.96,1.35)$ \\
\hline $3 r d$ & $1.07(0.91,1.26)$ & $1.07(0.91,1.26)$ \\
\hline 4th & $1.12(0.96,1.30)$ & $1.13(0.97,1.32)$ \\
\hline 5th & - & - \\
\hline \multicolumn{3}{|l|}{ Mental } \\
\hline $1 \mathrm{st}$ & $1.39(1.17,1.65)$ & $1.38(1.16,1.64)$ \\
\hline 2nd & $1.20(1.02,1.40)$ & $1.20(1.02,1.40)$ \\
\hline $3 r d$ & $1.10(0.95,1.28)$ & $1.08(0.93,1.26)$ \\
\hline 4th & $1.03(0.89,1.20)$ & $1.03(0.89,1.19)$ \\
\hline 5th & - & - \\
\hline \multicolumn{3}{|l|}{ Symptoms } \\
\hline $1 \mathrm{st}$ & $1.14(0.94,1.38)$ & $1.16(0.96,1.41)$ \\
\hline 2nd & $0.94(0.78,1.12)$ & $0.94(0.79,1.13)$ \\
\hline $3 r d$ & $1.02(0.86,1.20)$ & $1.02(0.87,1.21)$ \\
\hline 4th & $0.92(0.78,1.07)$ & $0.91(0.78,1.06)$ \\
\hline 5th & - & - \\
\hline \multicolumn{3}{|l|}{ Effects } \\
\hline $1 \mathrm{st}$ & $0.82(0.67,1.01)$ & $0.80(0.65,0.99)$ \\
\hline 2nd & $0.90(0.75,1.08)$ & $0.87(0.72,1.05)$ \\
\hline $3 r d$ & $0.94(0.79,1.11)$ & $0.94(0.79,1.12)$ \\
\hline 4 th & $0.88(0.75,1.04)$ & $0.88(0.75,1.04)$ \\
\hline 5th & - & - \\
\hline \multicolumn{3}{|l|}{ Burden } \\
\hline $1 s t$ & $1.00(0.84,1.20)$ & $1.01(0.84,1.21)$ \\
\hline 2nd & $1.08(0.91,1.28)$ & $1.07(0.90,1.27)$ \\
\hline $3 r d$ & $0.92(0.78,1.09)$ & $0.92(0.78,1.09)$ \\
\hline 4th & $0.99(0.85,1.16)$ & $0.98(0.84,1.15)$ \\
\hline 5th & - & - \\
\hline Age, years & $1(0.99,1.01)$ & $1(0.99,1.01)$ \\
\hline \multicolumn{3}{|l|}{ Race } \\
\hline Caucasian & - & - \\
\hline African-American & $0.86(0.77,0.96)$ & $0.86(0.77,0.96)$ \\
\hline Hispanic & $0.85(0.73,0.98)$ & $0.85(0.73,0.98)$ \\
\hline Other & $0.62(0.51,0.76)$ & $0.62(0.50,0.76)$ \\
\hline \multicolumn{3}{|l|}{ Sex } \\
\hline Female & - & - \\
\hline Male & $0.92(0.84,1.02)$ & $0.91(0.83,1.01)$ \\
\hline \multicolumn{3}{|l|}{ Enrolled in Medicaid } \\
\hline No & - & - \\
\hline Yes & $1.06(0.94,1.19)$ & $1.07(0.95,1.20)$ \\
\hline Time on Dialysis (years) & $1.01(1.00,1.03)$ & $1.01(1.00,1.03)$ \\
\hline
\end{tabular}

Table 3 Adjusted Analyses for Risk of Hospitalization with and without Competing Mortality (Continued)

\begin{tabular}{lll}
\hline Quintile & $\begin{array}{l}\text { Adjusted HR } \\
(95 \% \mathrm{Cl})\end{array}$ & $\begin{array}{l}\text { Adjusted sdHR } \\
(95 \% \mathrm{Cl})\end{array}$ \\
\hline Kt $\mathrm{N}$ & $0.92(0.78,1.08)$ & $0.91(0.77,1.07)$ \\
Hemoglobin $(\mathrm{g} / \mathrm{dL})$ & $0.91(0.86,0.96)$ & $0.90(0.85,0.95)$ \\
Charlson comorbidity index & $1.05(1.02,1.09)$ & $1.06(1.02,1.09)$ \\
$\begin{array}{l}\text { Access Type } \\
\quad\end{array}$ & - \\
$\quad$ Catheter & - & $0.86(0.73,1.02)$ \\
\multicolumn{1}{c}{ Arterialvenous fistula } & $0.88(0.75,1.03)$ & $0.93(0.78,1.10)$ \\
\hline
\end{tabular}

Data expressed as hazard ratio (HR) for Cox Proportional Hazards Model [or subdistribution hazard ratio (sdHR) for competing risk model] and $95 \%$ confidence interval (Cl). Significant hazard ratios $(p<.05)$ indicated in bold Analyses conducted on complete cases, $n=2895$, and were adjusted for all KDQOL-36 subscales and covariates shown in table

hospitalization [36, 40]. Nearly two-thirds of the cohort experienced a hospitalization in 2012 which underscores the importance of developing interventions that add additional layers of support for high-risk patients at home and other non-acute settings. Our findings suggest that adding the SF-12 to risk factors identified in prior studies [41, 42], may offer a modest improvement in identification of high risk patients who may benefit from additional intervention and/or oversight to proactively address concerns early when they first arise and prevent hospitalizations. Because these patients tend to have multiple comorbidities, additional research on the role of distinct comorbidities (e.g., heart failure or cancer) on KDQOL-36 subscales may also enhance our ability to identify patients at risk of frequent hospitalizations for management of those comorbidities.

Although we identified association of SF-12 with death and/or hospitalization, the SF-12, as well as the other KDQOL-36 subscales, appear to only yield a modest improvement in prognostication of those outcomes in older dialysis patients. While additional studies are needed to confirm our findings for development of prognostic tools (e.g., external validation), our findings also suggest that aspects of health related quality of life that are most associated with adverse outcomes in older adults are not adequately measured by the KDQOL-36. The KDQOL-36 does not capture aspects of quality of life that are valued by older adults, such as social relationships, financial circumstances, independence, and positive outlook [43]. These aspects are measured in the Older People's Quality of Life Questionnaire (OPQOL) [43], and may enhance both model fit and prognostic accuracy. Additional research into the relationship of the OPQOL or other older adult-specific instruments with death and hospitalization in older dialysis patients is needed. 
Our study is the first to evaluate the relationship of KDQOL-36 subscales with adverse outcomes in a cohort limited to older adults receiving dialysis. However, there are limitations to consider when interpreting our results. First, we derived our cohort from a single LDO that provides for-profit dialysis services to more than one-third of the United States' dialysis population, and the average time on dialysis for cohort members was nearly 6 years. Thus, our results may not be generalizable to all dialysis patients aged $\geq 75$ years worldwide, particularly those who are new to dialysis, as well as, those receiving dialysis in the United States' non-profit dialysis organizations or federal programs. Still, we find the cohort characteristics to be similar to those for the overall population of older adults receiving maintenance dialysis registered in the United States Renal Data System [44]. Second, we selected a cohort who completed the KDQOL-36; therefore, these findings have limited generalizability to patients who are unable to complete the KDQOL-36, particularly older adults with dementia. For this subset of patients, a separate analysis using a HRQOL tool specific for people with dementia is more ideal because dementia contributes its own significant association with death and dialysis withdrawal rates [45, 46]. Third, not all unmeasured confounders or prognostic variables identified in previous research were available in the dataset, including new medical diagnoses, medications, blood pressure, weight gain, lean body mass, depression, social support, level of care (e.g., self-care or skilled nursing) and prior hospitalizations [47-49]. Fourth, we had insufficient data to report the most common reasons for hospitalization or death. Such granular data would be helpful in subsequent studies to elucidate if low health-related quality of life is associated with the onset of specific health events (e.g., cardiovascular event, including related death, or access-related infection). Finally, our analyses do not capture serial KDQOL-36 data so we did not test the association of worsening quality of life or functional status on mortality and hospitalizations. However, recent evidence suggests that a patient's most recent measure of quality of life is more predictive of mortality than the change in quality of life over time [37]. Finally, we acknowledge measurement error from the KDQOL-36 may bias our findings.

\section{Conclusion}

We report that among KDQOL-36 subscales, SF-12 PCS, has the potential to enhance prognostication of survival and future hospitalizations in older adults receiving dialysis. If validated in other studies, this finding may support routine quality of life assessments and integration of health-related quality of life and clinical data into prediction tools that ultimately enhance risk stratification and shared decision-making for older adult receiving maintenance dialysis.

\section{Additional file}

Additional file 1: Table S1. Baseline characteristics of cohort members included and excluded from analytic sample. Table S2. Unadjusted Hazard Ratios for Death and Hospitalization and Subdistribution Hazard Ratios for Hospitalization. Table S3. Adjusted regression models predicting death by quantile KDQOL-36 subscale score. Table S4. Effect Estimates for Covariates of Cox Model for Risk of Death. Table S5. Adjusted regression models predicting hospitalization by quantile KDQOL-36 subscale score. (DOCX $25 \mathrm{~kb})$

\section{Abbreviations}

AVF: Arteriovenous fistula; AVG: Arteriovenous graft; CMS: Centers for Medicare and Medicaid Services; KDQOL-36: Kidney Disease Quality of Life - 36 item instrument; LDO: Large dialysis organization; MCS: Mental component score; PCS: Physical component score; PD: Peritoneal dialysis; SD: Standard deviation; SF-12: Short Form - 12 item instrument; U. S.: United States

\section{Acknowledgements}

The authors acknowledge Dr. Ann O'Hare for her contribution to the work described here and her review of the manuscript. Data used for this study was provided by DaVita Clinical Research.

\section{Funding}

This study was funded by the National Institute on Aging [Claude D. Pepper Older Americans Independence Center (P30 AG028716), GEMSSTAR program R03 AG050834, and K24 AG049077-01A1], National Center for Advancing Translational Sciences (KL2TR001115), and the T. Franklin Williams Scholarship Award (funding provided by Atlantic Philanthropies, Inc., the John A. Hartford Foundation, the Alliance for Academic Internal Medicine-Association of Specialty Professors, and the American Society of Nephrology Foundation). The NIH (and other sponsors) did not have a role in study design, data collection, analysis, or interpretation, or manuscript preparation.

\section{Availability of data and materials}

The data that support the findings of this study are available from DaVita Clinical Research but restrictions apply to the availability of these data, which were used under license for the current study, and so are not publicly available. Data are potentially available from the authors upon reasonable request and with permission of DaVita Clinical Research.

\section{Authors' contributions}

$\mathrm{RH}$ developed study design, acquired data, interpretation of findings and preparation of manuscript. AL performed data management, analysis, and preparation of manuscript. CP supervised data analyses, provided

interpretation of findings, and revision of manuscript. CCE facilitated study design, provided interpretation of findings, and revision of manuscript. All authors read and approved the final manuscript.

\section{Ethics approval and consent to participate}

Given the nature of the study design, we did not obtain consent from all of the study participants. The Duke University Institutional Review Board waived the need for consent by study participants and approved this study. This analysis was permitted after IRB approval, completion of data license agreement and contract between Duke University and DaVita Clinical Research.

\section{Consent for publication}

Not Applicable.

\section{Competing interests}

The authors declare that they have no competing interests

\section{Publisher's Note}

Springer Nature remains neutral with regard to jurisdictional claims in published maps and institutional affiliations. 


\section{Author details}

'Durham VA Geriatric Research, Education and Clinical Center, 508 Fulton Street, Durham, NC 27705, USA. ²Duke University Medical Center, Division of Nephrology, Department of Medicine, Box DUMC 2747, 2424 Erwin Road Suite 605, Durham, NC 27710, USA. ${ }^{3}$ Duke University, Department of Biostatistics and Bioinformatics, Box DUMC 2721, 2424 Erwin Road, Suite 1102, Durham, NC 27710, USA. ${ }^{4}$ Duke University Medical Center, Division of Geriatrics, Department of Medicine, Box DUMC 3003, Durham, NC 27710, USA.

\section{Received: 29 August 2017 Accepted: 18 December 2017} Published online: 15 January 2018

\section{References}

1. Davison SN, Jassal SV. Supportive care: integration of patient-centered kidney care to manage symptoms and geriatric syndromes. Clinical journal of the American Society of Nephrology : CJASN. 2016;11(10):1882-91.

2. Unruh ML, Weisbord SD, Kimmel PL. Health-related quality of life in nephrology research and clinical practice. Semin Dial. 2005;18(2):82-90.

3. Couchoud C, Hemmelgarn B, Kotanko P, Germain MJ, Moranne O, Davison SN. Supportive care: time to change our prognostic tools and their use in CKD. Clinical journal of the American Society of Nephrology : CJASN. 2016; 11(10):1892-901.

4. Wood WA, Le-Rademacher J, Syrjala KL, Jim H, Jacobsen PB, Knight JM, Abidi MH, Wingard JR, Majhail NS, Geller NL, et al. Patient-reported physical functioning predicts the success of hematopoietic cell transplantation (BMT CTN 0902). Cancer. 2016;122(1):91-8.

5. Quinten C, Coens C, Mauer M, Comte S, Sprangers MA, Cleeland C, Osoba D, Bjordal K, Bottomley A, Groups EC. Baseline quality of life as a prognostic indicator of survival: a meta-analysis of individual patient data from EORTC clinical trials. The Lancet Oncology. 2009;10(9):865-71.

6. Porter AC, Lash JP, Xie D, Pan Q, DeLuca J, Kanthety R, Kusek JW, Lora CM, Nessel L, Ricardo AC, et al. Predictors and outcomes of health-related quality of life in adults with CKD. Clinical journal of the American Society of Nephrology : CJASN. 2016;11(7):1154-62.

7. Osthus TB, Preljevic VT, Sandvik L, Leivestad T, Nordhus IH, Dammen T, Os I. Mortality and health-related quality of life in prevalent dialysis patients: comparison between 12-items and 36-items short-form health survey. Health Qual Life Outcomes. 2012:10:46.

8. Mapes DL, Lopes AA, Satayathum S, KP MC, Goodkin DA, Locatelli F, Fukuhara S, Young EW, Kurokawa K, Saito A, et al. Health-related quality of life as a predictor of mortality and hospitalization: the dialysis outcomes and practice patterns study (DOPPS). Kidney Int. 2003:64(1):339-49.

9. Lacson E Jr, Xu J, Lin SF, Dean SG, Lazarus JM, Hakim RM. A comparison of SF-36 and SF-12 composite scores and subsequent hospitalization and mortality risks in long-term dialysis patients. Clinical journal of the American Society of Nephrology: CJASN. 2010:5(2):252-60

10. Hayashino Y, Fukuhara S, Akiba T, Akizawa T, Asano Y, Saito S, Kurokawa K Low health-related quality of life is associated with all-cause mortality in patients with diabetes on haemodialysis: the Japan dialysis outcomes and practice pattern study. Diabetic medicine : a journal of the British Diabetic Association. 2009;26(9):921-7.

11. Haring R, Feng YS, Moock J, Volzke H, Dorr M, Nauck M, Wallaschofski H, Kohlmann T. Self-perceived quality of life predicts mortality risk better than a multi-biomarker panel, but the combination of both does best. BMC Med Res Methodol. 2011;11:103.

12. Han PK, Lee M, Reeve BB, Mariotto AB, Wang Z, Hays RD, Yabroff KR, Topor M, Feuer EJ. Development of a prognostic model for six-month mortality in older adults with declining health. J Pain Symptom Manag. 2012;43(3):527-39.

13. Dorr DA, Jones SS, Burns L, Donnelly SM, Brunker CP, Wilcox A, Clayton PD. Use of health-related, quality-of-life metrics to predict mortality and hospitalizations in community-dwelling seniors. J Am Geriatr Soc. 2006; 54(4):667-73.

14. Kalantar-Zadeh K, Kopple JD, Block G, Humphreys MH. Association among SF36 quality of life measures and nutrition, hospitalization, and mortality in hemodialysis. Journal of the American Society of Nephrology : JASN. 2001; 12(12):2797-806

15. Knight EL, Ofsthun N, Teng M, Lazarus JM, Curhan GC. The association between mental health, physical function, and hemodialysis mortality. Kidney Int. 2003;63(5):1843-51.
16. Lopes AA, Bragg-Gresham JL, Satayathum S, McCullough K, Pifer T, Goodkin DA, Mapes DL, Young EW, Wolfe RA, Held PJ, et al. Healthrelated quality of life and associated outcomes among hemodialysis patients of different ethnicities in the United States: the dialysis outcomes and practice patterns study (DOPPS). American journal of kidney diseases : the official journal of the National Kidney Foundation. 2003:41(3):605-15.

17. Lowrie EG, Curtin RB, LePain N, Schatell D. Medical outcomes study short form-36: a consistent and powerful predictor of morbidity and mortality in dialysis patients. American journal of kidney diseases : the official journal of the National Kidney Foundation. 2003:41(6):1286-92.

18. Tsai YC, Hung CC, Hwang SJ, Wang SL, Hsiao SM, Lin MY, Kung LF, Hsiao $\mathrm{PN}$, Chen HC. Quality of life predicts risks of end-stage renal disease and mortality in patients with chronic kidney disease. Nephrology, dialysis, transplantation : official publication of the European Dialysis and Transplant Association - European Renal Association. 2010;25(5):1621-6.

19. Wick JP, Turin TC, Faris PD, MacRae JM, Weaver RG, Tonelli M, Manns BJ, Hemmelgarn BR. A clinical risk prediction tool for 6-month mortality after dialysis initiation among older adults. American journal of kidney diseases : the official journal of the National Kidney Foundation. 2016;69(5):568-75.

20. Weiss JW, Platt RW, Thorp ML, Yang X, Smith DH, Petrik A, Eckstrom E, Morris C, O'Hare AM, Johnson ES. Predicting mortality in older adults with kidney disease: a pragmatic prediction model. J Am Geriatr Soc. 2015;63(3):508-15.

21. Thamer M, Kaufman JS, Zhang Y, Zhang Q, Cotter DJ, Bang H. Predicting early death among elderly dialysis patients: development and validation of a risk score to assist shared decision making for dialysis initiation. American journal of kidney diseases : the official journal of the National Kidney Foundation. 2015:66(6):1024-32.

22. Cohen LM, Ruthazer R, Moss AH, Germain MJ. Predicting six-month mortality for patients who are on maintenance hemodialysis. Clinical journal of the American Society of Nephrology : CJASN. 2010;5(1):72-9.

23. Couchoud C, Labeeuw M, Moranne O, Allot V, Esnault V, Frimat L, Stengel B. A clinical score to predict 6-month prognosis in elderly patients starting dialysis for end-stage renal disease. Nephrology Dialysis Transplantation. 2009;24(5):1553-61.

24. Lee SJ, Lindquist K, Segal MR, Covinsky KE. Development and validation of a prognostic index for 4-year mortality in older adults. JAMA. 2006;295(7):801-8.

25. Hays RD, Kallich JD, Mapes DL, Coons SJ, Carter WB. Development of the kidney disease quality of life (KDQOL) instrument. Quality of life research : an international journal of quality of life aspects of treatment, care and rehabilitation. 1994;3(5):329-38.

26. Kidney Disease Quality of Life Instrument (KDQOL): Scoring the KDQOL-36 [https://www.rand.org/health/surveys_tools/kdqol.html]. Accessed 23 Oct 2017

27. Charlson ME, Pompei P, Ales KL, MacKenzie CR. A new method of classifying prognostic comorbidity in longitudinal studies: development and validation. J Chronic Dis. 1987;40(5):373-83.

28. Goldwasser P, Mittman N, Antignani A, Burrell D, Michel MA, Collier J, Avram MM. Predictors of mortality in hemodialysis patients. Journal of the American Society of Nephrology : JASN. 1993;3(9):1613-22.

29. Kurella Tamura M, Covinsky KE, Chertow GM, Yaffe K, Landefeld CS, McCulloch CE. Functional status of elderly adults before and after initiation of dialysis. N Engl J Med. 2009;361(16):1539-47.

30. Rattanasompattikul M, Feroze U, Molnar MZ, Dukkipati R, Kovesdy CP, Nissenson AR, Norris KC, Kopple JD, Kalantar-Zadeh K. Charlson comorbidity score is a strong predictor of mortality in hemodialysis patients. Int Urol Nephrol. 2012;44(6):1813-23.

31. Wasse $H$, Kutner $N$, Zhang $R$, Huang $Y$. Association of initial hemodialysis vascular access with patient-reported health status and quality of life. Clinical journal of the American Society of Nephrology CJASN. 2007;2(4):708-14.

32. Steyerberg EW. Clinical prediction models a practical approach to development, validation, and updating. In: Statistics for biology and health. New York: Springer; 2009. p. 1. online resource (xxviii, 497 p.)

33. Harrell FE Jr, Lee KL, Mark DB. Multivariable prognostic models: issues in developing models, evaluating assumptions and adequacy, and measuring and reducing errors. Stat Med. 1996;15(4):361-87.

34. Hsu JY, Roy JA, Xie D, Yang W, Shou H, Anderson AH, Landis JR, Jepson C, Wolf M, Isakova T, et al. Statistical methods for cohort studies of CKD: survival analysis in the setting of competing risks. Clinical journal of the American Society of Nephrology : CJASN. 2017;12(7):1181-9. 
35. Noordzij M, Leffondre K, van Stralen K, Zoccali C, Dekker FW, Jager KJ When do we need competing risks methods for survival analysis in nephrology? Nephrology, dialysis, transplantation : official publication of the European Dialysis and Transplant Association - European Renal Association. 2013;28(11):2670-7.

36. McAdams-DeMarco MA, Law A, Salter ML, Boyarsky B, Gimenez L, Jaar BG, Walston JD, Segev DL. Frailty as a novel predictor of mortality and hospitalization in individuals of all ages undergoing hemodialysis. J Am Geriatr Soc. 2013;61(6):896-901.

37. Perl J, Karaboyas A, Morgenstern H, Sen A, Rayner HC, Vanholder RC, Combe C, Hasegawa T, Finkelstein FO, Lopes AA, et al. Association between changes in quality of life and mortality in hemodialysis patients: results from the DOPPS. Nephrology, dialysis, transplantation : official publication of the European Dialysis and Transplant Association - European Renal Association. 2017:32(3):521-7.

38. Lee $Y$. The predictive value of self assessed general, physical, and mental health on functional decline and mortality in older adults. J Epidemiol Community Health. 2000;54(2):123-9.

39. Lee SY, Yang DH, Hwang E, Kang SH, Park SH, Kim TW, Lee DH, Park K, Kim $J C$. The prevalence, association, and clinical outcomes of frailty in maintenance dialysis patients. Journal of renal nutrition : the official journal of the Council on Renal Nutrition of the National Kidney Foundation. 2017; 27(2):106-12.

40. Fried LP, Tangen CM, Walston J, Newman AB, Hirsch C, Gottdiener J, Seeman T, Tracy R, Kop WJ, Burke G, et al. Frailty in older adults: evidence for a phenotype. J Gerontol A Biol Sci Med Sci. 2001:56(3):M146-56.

41. Usvyat LA, Kooman JP, van der Sande FM, Wang Y, Maddux FW, Levin NW, Kotanko P. Dynamics of hospitalizations in hemodialysis patients: results from a large US provider. Nephrology, dialysis, transplantation : official publication of the European Dialysis and Transplant Association - European Renal Association. 2014;29(2):442-8.

42. Sun Y, Kassam H, Adeniyi M, Martinez M, Agaba El, Onime A, Servilla KS, Raj DS, Murata GH, Tzamaloukas AH. Hospital admissions in elderly patients on chronic hemodialysis. Int Urol Nephrol. 2011;43(4):1229-36.

43. Bowling A, Hankins M, Windle G, Bilotta C, Grant R. A short measure of quality of life in older age: the performance of the brief older People's quality of life questionnaire (OPOOL-brief). Arch Gerontol Geriatr. 2013:56(1):181-7.

44. U.S. Renal Data System. 2014 USRDS Annual Data Report. Bethesda: Atlas of Chronic Kidney Disease and End-Stage Renal Disease in the United States; 2014.

45. Kurella M, Mapes DL, Port FK, Chertow GM. Correlates and outcomes of dementia among dialysis patients: the dialysis outcomes and practice patterns study. Nephrology, dialysis, transplantation : official publication of the European Dialysis and Transplant Association - European Renal Association. 2006;21(9):2543-8.

46. Smith SC, Lamping DL, Banerjee S, Harwood R, Foley B, Smith P, Cook JC, Murray J, Prince $M$, Levin $E$, et al. Measurement of health-related quality of life for people with dementia: development of a new instrument (DEMQOL) and an evaluation of current methodology. Health technology assessment (Winchester, England). 2005;9(10):1-93. iii-iv

47. Flythe JE, Hilbert J, Kshirsagar AV, Gilet CA. Psychosocial factors and 30-day hospital readmission among individuals receiving maintenance dialysis: a prospective study. Am J Nephrol. 2017;45(o):400-8.

48. Jencks SF, Williams MV, Coleman EA. Rehospitalizations among patients in the Medicare fee-for-service program. N Engl J Med. 2009;360(14):1418-28,

49. Uswyat LA, Barth C, Bayh I, Etter M, von Gersdorff GD, Grassmann A, Guinsburg AM, Lam M, Marcelli D, Marelli C, et al. Interdialytic weight gain, systolic blood pressure, serum albumin, and C-reactive protein levels change in chronic dialysis patients prior to death. Kidney Int. 2013;84(1):149-57.

\section{Submit your next manuscript to BioMed Central and we will help you at every step:}

- We accept pre-submission inquiries

- Our selector tool helps you to find the most relevant journal

- We provide round the clock customer support

- Convenient online submission

- Thorough peer review

- Inclusion in PubMed and all major indexing services

- Maximum visibility for your research

Submit your manuscript at www.biomedcentral.com/submit

C Biomed Central 